\title{
A Framework for Technological Learning in the Supply Chain: a Case Study on CdTe Photovoltaics
}

\author{
Joseph D. Bergesen ${ }^{\mathrm{a}} \&$ Sangwon Suh ${ }^{\mathrm{a}^{*}}$ \\ ${ }^{a}$ Bren School of Environmental Science \& Management, 2400 Bren Hall, University of \\ California, Santa Barbara, CA 93106-5131, USA \\ ${ }^{*}$ Corresponding author, suh@bren.ucsb.edu
}

\begin{abstract}
:
Accounting for technological changes and innovation is important when assessing the implications of rapidly-developing greenhouse gas (GHG) mitigation technologies. Technological learning curves have been commonly used as a tool to understand technological change as a function of cumulative production. Traditional learning curve approaches, however, do not distinguish the direct and upstream, supply chain technological changes by which cost reductions are achieved. While recent advances in learning curves have focused on distinguishing the different physical and economic drivers of learning, forecasted technological changes have not been applied to estimate the potential changes in the environmental performance of a technology. This article illustrates how distinguishing the different effects of technological learning throughout the supply chain can help assess the changing costs, environmental impacts and natural resource implications of technologies as they develop. We propose a mathematical framework to distinguish the effects of learning on the direct inputs to a technology from the effects of learning on value added, and we incorporate those effects throughout the supply chain of a technology using a life cycle assessment (LCA) framework. An example for cadmium telluride (CdTe) photovoltaics (PV) illustrates how the proposed framework can be implemented. Results show that that life cycle GHG emissions can decrease at least $40 \%$ and costs can decrease at least $50 \%$ as cumulative production of CdTe reaches $100 \mathrm{GW}$. Technological learning in
\end{abstract}


supply chain processes can further reduce emissions and costs by up to 1-2\%. Lastly, we discuss the implications of using this new technological learning framework in the long-term assessment of the costs, environmental impacts and resource requirements of technologies using life-cycle assessment.

Keywords: life cycle assessment (LCA); learning curve, technological learning; photovoltaics; supply chain 


\section{Introduction}

Climate stabilization scenarios generally assume an unprecedented scale of deployment of low-carbon energy technologies over the coming decades [1]. The International Energy Agency (IEA)'s 2 degree scenario, for example, postulates that the share of non-hydroelectric renewables in electricity generation increases to over $50 \%$ by 2050 , up from less than $2 \%$ today [2]. Therefore, it is important to understand the economic, environmental, and resource implications of low-carbon technologies to be deployed in the future [3]. Empirical studies suggest that the evolutionary trajectory of a technology is closely connected to the cumulative volume of projection [4-6]. It is, therefore, an important challenge to forecast the evolutionary path of the environmental performance of these technologies as they are deployed at an unprecedented scale over the next 30-40 years, particularly under climate and natural resource constraints [7]. For example, recent studies suggest that light emitting diodes (LEDs) and photovoltaics (PVs) may see substantial improvements in their embodied energy, costs, resource requirements and environmental impacts over the coming decades $[3,8,9]$. Further improvements are expected, and thus it would be inaccurate to base policy or investment decisions on present day costs and technological capabilities alone.

Technological learning curve literature has shown a remarkable relationship between the costs of technologies and its cumulative production volume, otherwise known as "learning-bydoing" $[4,5,10]$. In forecasting the future environmental impacts of technologies, learning curves are limited in their usefulness. First, they view the drivers of cost reduction as a black box. Learning curves forecast the cost of technologies over time due to increased production volume, but provide no information on how the quantities of direct inputs to producing a technology might change to achieve these reductions--information that is necessary to estimate the changes in environmental impact due to learning. In reality, cost reductions can be realized by a number of possible mechanisms, including increased labor productivity, economies of scale, improved materials and energy efficiency and productivity, and changes in the price of inputs. Second, 
current learning curve approaches ignore the effect of 'co-evolution' through supply chain: if the cost of a technology is closely connected to the cumulative volume of production, the same should apply throughout the supply chain. In this case, one technology can benefit from the growth of another technology that demands the same input, contributing to the increase in cumulative production of that input. Third, knowledge of cost reductions alone is not sufficient to understand how the supply chain, natural resource requirements and environmental impacts of a technology will change as its cost is reduced.

Recent advances in learning curves have endeavored to distinguish the different drivers of technological change that contribute to observed learning effects, and to understand how the physical and design attributes of technologies can help predict learning rates. For example, van Eijck et al. recently separated the effects of yield increases from labor productivity on the learning curves of second generation biofuels [11], and Zheng and Kammen similarly separated the effects of economies of scale from module efficiency improvements in thin-film PV cost reductions[12], both of which are examples of the increasing consideration of multiple technological and economic factors in understanding learning curves [13-16]. Also, Rochedo and Szklo showed how the inherent physical properties of solvents could be used to construct a bottom-up learning curve model for carbon capture technologies, and in turn predicted similar cost reductions as empirical studies [17]. Similarly, McNerney et al. showed that the learning rates of technologies could be predicted based on the complexity of their physical design [18]. While these examples show increasing interest in basing learning analyses on physical changes, little work has been done to show how the different drivers of learning can influence the environmental impacts of technologies as they learn [19,20], and none consider how learning can occur throughout the supply chain of technologies.

This article addresses this gap in the literature by proposing a generalized mathematical framework for considering learning effects throughout the supply chain of a technology, and for calculating the life-cycle impacts of technologies as they learn. In particular we aim to separate 
the effects of learning on value added (e.g. labor and profit) from the effects of learning on the quantities of direct and supply chain inputs required to produce a technology. We illustrate the different effects of learning on environmental impacts with a numerical example for thin-film cadmium telluride (CdTe) PV modules. Lastly, we identify and discuss the major findings and potential policy implications of this technological learning framework in assessing the environmental impacts of technologies using life-cycle assessment (LCA).

\section{Overview of learning curves and their applications}

In this section we briefly review some of the major approaches to modeling technological change, and we highlight recent developments that may be useful for separating the different drivers of technological change that lead to both changing costs and changing environmental impacts of technologies.

\subsection{Wright's law and its extensions}

The nature of technological change was famously characterized by Theodore Wright in 1936, who observed that the unit costs of producing airplanes, particularly labor costs, declined as a power law function of cumulative production [4]. Cumulative production, as explained by Arrow, serves as a proxy for the cumulative technical knowledge and experience acquired in producing a technology [10]. Similarly, Gordon Moore, co-founder of the Intel Corporation, observed that the number of transistors in an integrated circuit doubled every two years, with the implication that costs of circuits decline as a function of only time [21]. Wright's law and Moore's law, as they came to be known, have both been used and expounded upon to model the

price reductions of technologies endogenously as they are scaled up, particularly in the context of energy policy scenarios $[22,23]$. In Wright's law, shown in equation $(1)$, the cost $(C)$ of a technology in time $(t)$ is a function of the initial cost $\left(C_{0}\right)$, cumulative production $(x)$, and an empirically observed learning parameter $(b)$. 


$$
C_{t}=C_{0}\left(\frac{x_{t}}{x_{0}}\right)^{b}
$$

The learning rate (LR), the relative cost reduction from a doubling of cumulative production, is calculated by $L R=1-2^{b}$. The greater the learning rate is the faster are the cost reductions. Argote and Epple observed that the learning rates of different industries and organizations vary considerably [24]. Bernt (1991) shows that a learning curve could be derived from a Cobb Douglas production function, lending theoretical credence to the concept [25]. Others have proposed related models that combine variables of time, cumulative production and economies of scale to explain observed cost curves [26-28]. McNerney et al. showed that learning rates were related the design complexity of a product [18]. In a recent article, Nagy et al. [5] analyzed price data on 62 different technologies and found that Wright's law statistically outperformed Moore's law and all of the more complicated multiple-factor learning models in explaining observed price reductions. The results of Nagy and colleagues imply that cumulative production in particular is the most accurate proxy for the amount of effort expended towards finding innovations that lead to cost reductions.

Learning curves have been frequently used to model the future costs of energy technologies in energy policy, and to forecast future energy mixes based on the projected costs of technologies [29]. The MARKAL model is a major example of how learning curves are used within a linear programming framework [23]. Berglund and Söderholm (2006) provide a review of learning models used in energy policy, analyzing how learning-by-doing has been introduced into bottom-up energy models by including additional factors like investment in research and development $(\mathrm{R} \& \mathrm{D})$ that leads to increased knowledge stock and potentially faster cost reductions [29]. Pan [30] and Pan and Kohler [31] developed a framework to consider how learning curve can be used to update input-output coefficients to model the long-term costs of energy technologies. Pan and Kohler also argued that logistic functions rather than power law functions might better predict price declines from learning by including parameters for $R \& D$ 
investment, time and natural or physical limits to technological changes in addition to simply cumulative production.

Ferioli et al. proposed a modified version of Wright's law, where the total observed cost reduction for a technology is a result of the combined learning effect of all of the direct inputs to a technology (e.g. materials, energy and labor) [32].

$$
C_{t}=\sum_{i=1}^{n} a_{i} c_{i, 0}\left(\frac{x_{i, t}}{x_{i, 0}}\right)^{b_{i}}
$$

Equation Error! Reference source not found. 2 presents the component learning hypothesis, where the index $i$ represents each of $n$ direct inputs required to produce a technology, $c_{0 i}$ and $a_{i}$ represent the initial cost and quantity of each component, $x_{i, t}$ is the cumulative production of each component and $b_{i}$ is the learning parameter of each component. Note that equation 2 has been modified from Ferioli et al in order to use a notation consistent with the equations presented later in this article. In this formulation, learning effects for well-established components are not noticeable, while others components at an earlier stage of development show more noticeable cost reductions. Ferioli et al. [32] and Yu et al. [33] use this kind of component thinking as a possible explanation for some variations in learning curves that do not behave as a simple power law. Yu et al. also apply a multifactor learning curve that accounts for changes in input costs and prices (e.g. silicon and silver) as well as returns-to-scale effects to explain some of the other variations in PV costs over recent years [33].

A major limitation of learning curves based on Wright's law is that they are unable to distinguish the different underlying changes that lead to overall cost reductions: changes in the quantities of direct inputs required, changes in the direct value added (labor productivity and profit margin) or either of these changes in production processes upstream in the supply chain.

\subsection{Technological change and learning curves in LCA}


Evaluating the environmental impacts of emerging technologies or technologies that are rapidly expanding, such as renewable energy technologies, requires a prospective modeling of how total costs and inputs change with scale and experience [6,34]. In the field of LCA, Sanden and Karlström notably used learning curves to show how investments in the production of alternative technologies like fuel-cell vehicles could lead to those technologies becoming competitive, resulting in environmental benefits if they displace fossil-fuel based technologies[35]. Their analysis, however, did not consider how the direct or supply chain inputs to alternative technologies would change as they progressed down their learning curve. Currently, researchers are beginning to use learning curves and power law relationships to explain and forecast changes in energy and materials inputs as production processes are scaled up and as cumulative production increases [6,36]. For example, scale is expected to have a significant effect on the costs and embodied impacts of products based on nanotechnology, due to increasing experience and increasing viability of recycling feedstock with scale [6,37]. Also, power law relationships have been observed in the reduction of the embodied environmental impacts of wind turbines both as turbine rotor size increases, and as cumulative experience increases [38]. Similarly, the material and fuel inputs required for heat pumps, furnaces and engines are seen to decline as a power law as their mass and cumulative production increases [36,39]. These studies suggest that power-law relationships can be useful for extrapolating the changes in physical inputs to technologies as they scale, in addition describing reductions in costs. Lastly, Dietzenbacher outlined an input-output approach for the "spillover" of innovation from one product or sector to another [40]. This framework can be used to analyze how cost reductions in one sector propagate throughout the economy, leading to cost reductions and changes in demand in other sectors.

\section{Methodological framework for supply chain learning}


This section outlines a mathematical framework for considering technological learning throughout the supply chain of a technology and computing the changing environmental impacts of technologies as cumulative production increases. This framework can be used to incorporate endogenous technological learning into energy scenario models that not only consider costs, but also environmental impacts and resource constraints.

\subsection{Mathematical framework for supply chain learning curves}

The objective of this framework is to decompose technology learning into its subcomponents, namely the changes to value added and quantities of intermediate inputs, and to show how such decomposition can help understand the implications of changes occurring both within and the given technology and throughout its supply chain on its costs and environmental impacts. The learning effects that we would like to capture are:

a) Intermediate Input Learning (IIL). This effect captures changes in the intermediate input intensity and efficiency of a product, process or technology. IIL captures the hypothesis that firms often learn to use less of each direct input for as cumulative experience increases, potentially reducing both costs and life-cycle environmental impacts. IIL includes materials and energy efficiency, materials substitution, and economies of scale.

b) Value Added Learning (VAL). This affect captures changes in the amounts of labor costs and profit margin for a product, process or technology. VAL is relevant for cost but not for life-cycle environmental impacts. VAL includes more efficient use of labor as the cumulative production of a technology increases, and can also include changes in profit margin.

c) Supply chain IIL and VAL. As presented above, IIL and VAL do not consider changes in the volume of production and corresponding learning that occur in the many products that are required indirectly in the supply chain of a technology. For example, the price of semiconductors might decline as they are demanded by PV technologies, also potentially 
lowering the costs of computers. This effect highlights the need to consider the rest of the economy in understanding the cost and intermediate requirements for a given technology. Therefore, we extend the learning curve model to an economy-wide model with a higherlevel technology specification given to the foreground technologies following the hybrid LCA tradition [41].

Table 1 summarizes each of these learning effects and gives an example for the PV supply chain. 
Table 1. Summary of supply chain learning effects.

\begin{tabular}{|c|c|c|c|c|}
\hline & \multicolumn{2}{|c|}{ Direct } & \multicolumn{2}{|c|}{ Supply-chain } \\
\hline & Direct VAL & Direct IIL & $\begin{array}{c}\text { Supply-chain } \\
\text { VAL }\end{array}$ & Supply-Chain IIL \\
\hline Definition & $\begin{array}{l}\text { Change in } \\
\text { quantity of labor } \\
\text { or profit per unit } \\
\text { output }\end{array}$ & $\begin{array}{l}\text { Change in } \\
\text { quantity of } \\
\text { intermediate } \\
\text { inputs required } \\
\text { per unit output }\end{array}$ & $\begin{array}{l}\text { Change in } \\
\text { quantity of labor } \\
\text { or profit required } \\
\text { by products } \\
\text { upstream in } \\
\text { supply-chain }\end{array}$ & $\begin{array}{l}\text { Change in quantity } \\
\text { of intermediate } \\
\text { inputs required by } \\
\text { products upstream } \\
\text { in supply-chain }\end{array}$ \\
\hline Example & $\begin{array}{l}\text { Increased labor } \\
\text { efficiency in PV } \\
\text { module } \\
\text { production }\end{array}$ & $\begin{array}{l}\text { Reduction in mass } \\
\text { of CdTe per } \mathrm{m}^{2} \text { of } \\
\mathrm{PV} \text { module }\end{array}$ & $\begin{array}{l}\text { Change in margin } \\
\text { or labor per } \mathrm{kg} \\
\text { CdTe produced }\end{array}$ & $\begin{array}{l}\text { Reduction in } \\
\text { electricity per kg of } \\
\text { CdTe produced }\end{array}$ \\
\hline Affects Costs? & Yes & Yes & Yes & Yes \\
\hline $\begin{array}{l}\text { Affects LCA } \\
\text { results? }\end{array}$ & No & Yes & No & Yes \\
\hline $\begin{array}{l}\text { Graphical } \\
\text { example }\end{array}$ & $\begin{array}{l}\$ 53 \rightarrow \$ 23 \\
\text { labor \& } \\
\text { margin }\end{array}$ & & $\begin{array}{l}\$ 130 \rightarrow \$ 100 \\
\text { labor \& } \\
\text { margin per kg }\end{array}$ & \\
\hline $\begin{array}{l}\text { CdTe } \\
\text { module }\end{array}$ & & $\begin{array}{l}15 \mathrm{~g} \rightarrow 6 \mathrm{~g} \\
\mathrm{CdTe}\end{array}$ & & $\begin{array}{l}12 \mathrm{kWh} \rightarrow \\
10 \mathrm{kWh} \\
\text { electricity }\end{array}$ \\
\hline
\end{tabular}

This section integrates two different mathematical representations for the cost of a technology over time to derive a supply-chain learning curve equation. First, we extend Wright's conventional learning law to consider the multiple technologies in the supply chain. Second, we employ an input-output (IO) based supply-chain cost equation to express a technology's cost as the sum of the value added of all the technologies in its supply chain. Lastly, we show how the 
supply-chain learning curve can be used to calculate the life-cycle environmental impacts of a technology over time.

In the conventional learning curve model as presented in equation (1), the cost of a technology in time $t$ is a function of the initial $\operatorname{cost} C_{0}$, cumulative production at time $t\left(x_{t}\right)$, the initial cumulative production $x_{0}$, and an empirically observed learning parameter $b$. Wright's law considers the case of just a single technology. To extend the model to the multiple technologies embedded in the supply chain, we define the cost of technology $k$ as a function of the cumulative production of $k$ at time $t$ such that

$$
C\left(x_{k, t}\right)=C_{k, 0}\left(\frac{x_{k, t}}{x_{k, 0}}\right)^{b_{k}}
$$

In an alternative representation, the cost of technology $k$ at time $t$ can be expressed as a function of the price of direct inputs to $k$, the quantity of direct inputs to $k$, and the direct value-added of $k$ :

$$
C\left(x_{k, t}\right)=\sum_{i} p_{i, t} a_{i, k, t}+v_{k, t}
$$

In equation (4), $p_{i, t}$ is the unit price of direct input $i, a_{i, k, t}$ is the quantity of direct input $i$ to produce a unit of $k$, and $v_{k, t}$ is the direct value-added per unit of $k$ at time $t$. Next, when considering the entire supply chain or life cycle of a product, the unit price of each input $i$ can in turn be further broken down into its direct value-added and the costs of its direct inputs $j$ in the same way:

$$
p_{i, t}=\sum_{j} p_{j, t} a_{j, i, t}+v_{i, t}
$$

This relationship propagates indefinitely, throughout the upstream inputs in the supply chain of technology $k$. For the sake of convenience, let us define $l_{i, k, t}$ as the total direct and indirect quantities of input $i$ needed to produce a unit of $k$ at time $t$, which allows us to rewrite equation (4) as a function of only the quantities and value added of supply-chain inputs:

$$
C\left(x_{k, t}\right)=\sum_{i} v_{i, t} l_{i, k, t}+v_{k, t}
$$


The values of $l_{i, k, t}$ can be calculated using an input-output framework, where $l_{j, i, t}$ is an element of the Leontief inverse, as derived in equations S1-S3 of the supplementary information (SI) [42]. As it will be shown later, it is useful to further decompose the right-hand-side of equation (6) into direct inputs for $k$, indirect inputs and the associated value added such that:

$$
C_{k, t}=\sum_{i} \sum_{j}\left(v_{j, t} l_{j, i, t}+v_{i, t}\right) a_{i, k, t}+v_{k, t}
$$

Now that we have decomposed the supply-chain cost of technology $k$ into its direct value added, direct inputs, supply-chain value added and supply-chain inputs, we can introduce learning factors affecting each term of equation (7). First, we assume that the intermediate inputs to a technology to decline as a power law, similar to the conventional Wright's law. Here the amount of direct input $i$ required to produce $j$ at time $t\left(a_{i, j, t}\right)$ is a function of initial amount of input $i$ to $j$ $\left(a_{i, j, 0}\right)$, the initial cumulative production of $j\left(x_{j, 0}\right)$, the cumulative production of $j$ at time $t\left(x_{j, t}\right)$, and a learning parameter for every particular $i-j$ combination $\beta_{i, j}$ such that

$$
a_{i, j, t}=a_{i, j, 0}\left(\frac{x_{j, t}}{x_{j, 0}}\right)^{\beta_{i, j}}
$$

Equation (8) represents the intermediate input learning (IIL) effect. For ILL, it is also important to consider that the inputs to a technology may not be reduced beyond certain limits due to physical (e.g. thermodynamic) or design constraints. If $a_{i, j, t}$ calculated using equation (8) is below such a limit for the case of a negative $\beta$, it should be replaced by the limit, $a_{i, j, t}^{*}$ such that:

$$
a_{i, j, t}=\left\{\begin{array}{ll}
a_{i, j, 0}\left(\frac{x_{j, t}}{x_{j, 0}}\right)^{\beta_{i, j}}, & a_{i, j, 0}\left(\frac{x_{j, t}}{x_{j, 0}}\right)^{\beta_{i, j}}>a_{i, j, t}^{*} \\
a_{i, j, t}^{*} & , a_{i, j, 0}\left(\frac{x_{j, t}}{x_{j, 0}}\right)^{\beta_{i, j}} \leq a_{i, j, t}^{*}
\end{array} .\right.
$$

Needless to mention, for the case of a positive $\beta$, if $a_{i, j, t}$ exceeds an upper limited it should be replaced by $a_{i, j, t}^{*}$. 
Similarly, one can assume that the amount of value-added to produce $j$ at time $t\left(v_{j, t}\right)$ is a function of the initial value-added $\left(v_{j, 0}\right)$, the initial cumulative production of $j\left(x_{j, 0}\right)$, the cumulative production of $j$ at time $t\left(x_{j, t}\right)$, and a value-added learning parameter $\left(\gamma_{j}\right)$ such that:

$$
v_{j, t}=v_{j, 0}\left(\frac{x_{j, t}}{x_{j, 0}}\right)^{\gamma_{j}}
$$

Equation (10) represents the value added learning (VAL) effect. Inserting the learning factors expressed by equations (9) and (10) into the supply-chain cost equation, equation (7), yields a complete supply-chain learning curve equation that separates direct VAL from direct IIL and the indirect learning effects:

$$
\begin{gathered}
C_{k, t}=\overbrace{v_{k, 0}\left(\frac{x_{k, t}}{x_{k, 0}}\right)^{\gamma_{k}}+}^{\text {Direct VAL }} \\
\sum_{i} \overbrace{j} \overbrace{a_{i, k, 0}\left(\frac{x_{k, t}}{x_{k, 0}}\right)^{\beta_{i, k}}}^{\text {Direct IIL }}[\overbrace{v_{i, 0}\left(\frac{x_{i, t}}{x_{i, 0}}\right)^{\gamma_{i}}}^{\text {First tier indirect VAL }}+\overbrace{v_{j, 0}\left(\frac{x_{j, t}}{x_{j, 0}}\right)^{\gamma_{j}} l_{j, i, t}}^{\text {VAL and IIL of the rest }}] .
\end{gathered}
$$

In equation (11), the cost of producing $k$ is not only a function of the cumulative production of $k$ itself, but it is also dependent on the cumulative production of technologies throughout the rest of its supply chain. The values of $l_{j, i, t}$ can be calculated using equations S1-S3 of the SI.

Finally, the total embodied, or life-cycle, environmental emissions or resource requirements $m_{p, k, t}$ of technology $k$ are

$$
m_{p, k, t}=\sum_{i}\left(b_{p, i, t} l_{i, k, t}+b_{p, k, t}\right) y_{k, t}
$$

where $b_{p, i, t}$ is the direct environmental intervention of each product in the economy for a given environmental exchange $p$, and $y_{k, t}$ is the final demand for technology $k$. It is important to remember that the direct environmental intervention $b_{p, i, t}$ of a process $i$ in time $t$ may change along with the inputs to that product $a_{i, j, t}$. For example, if efficiency of a fuel burning process 
improves (requiring less fuel per unit output), greenhouse gases and other pollutant emissions associated with that process will also be reduced.

\section{Learning example for CdTe PV}

Next, we present an example to illustrate how the effects of learning throughout the supply chain of technology can contribute to the observed learning effects for cadmium telluride (CdTe) PV. From 2006-2013, the observed cost learning rate for thin-film PV was around 19\% (b $=-0.28$ [43]. Using a scenario analysis, we estimate the IIL and VAL parameters for direct and supply chain inputs in an attempt to reproduce the observed learning rate and estimate the expected life-cycle GHG emissions per Watt if cumulative capacity approaches $100 \mathrm{GW}$ by 2030 following IEA 2 degree scenario projections [2]. Over the course of this scenario, we use technology roadmaps to apply limits to future CdTe energy conversion efficiency, materials efficiency and value added, as shown in 
Table 2 [44]. Also we show how knowledge of the cost structure, supply chain requirements and potential technological limits of a product can be used to deconstruct the different effects of technology learning.

The major contributors to CdTe module costs and life-cycle GHG emissions are summarized in Table 2. This analysis considers learning effects in inputs that make up approximately $80 \%$ of module costs. To estimate the $\operatorname{IIL}(\beta)$ and $\operatorname{VAL}(\gamma)$ of inputs to PV modules we rely on previously published life-cycle analyses and cost benchmarking studies to track past changes in value added and materials and energy inputs to modules (Table 2) $[8,44-$ 47]. For example, typical module energy efficiency has improved from around $8 \%$ in 2004 to over $14.7 \%$ by 2014 , while at the same time cumulative production has increased by over a thousand times $[43,45,47,48]$. As module efficiency improves, fewer CdTe modules are needed to produce a Watt of power: $a_{\text {modules }, \text { Watt }}=1 /\left(\right.$ efficiency $\left.* 0.72 \mathrm{~m}^{2} * 1000 \mathrm{~W} / \mathrm{m}^{2}\right)$. Assuming that module efficiency improves as a function of cumulative production according to equation (9), ordinary least squared regression analysis can estimate that $\beta_{\text {modules,Watt }}=-0.08$. Similar analysis for other inputs yields the estimates of $\beta$ presented in Table 2. Details of these regressions are presented in the SI.

For this analysis, we vary the IIL and VAL parameters for supply chain processes, i.e. everything except PV modules production. This allows for an exploration of how learning in the supply chain of PV can influence observed learning rates over the course of a scenario. 
Table 2. Technological potentials and estimated or assumed learning parameters and future potentials for selected direct and indirect inputs to CdTe PV module production. More detailed cost and input information can be found in the supplementary information (SI).

\begin{tabular}{|c|c|c|c|c|}
\hline & \begin{tabular}{|l|} 
Historical $(=)$ or \\
assumed $(\sim)$ \\
learning parameter
\end{tabular} & Current status & $\begin{array}{l}\text { Future potential } \\
\text { or feasible limit }\end{array}$ & Data sources \\
\hline \multicolumn{5}{|c|}{ Direct inputs to module } \\
\hline $\begin{array}{l}\text { Energy conversion } \\
\text { efficiency }\end{array}$ & $\beta=0.080$ & $13-15 \%$ & $19 \%$ & $\begin{array}{l}\text { Previous LCAs and } \\
\text { benchmarking studies for } \\
\text { CdTe PV [44,45,47-49] }\end{array}$ \\
\hline $\begin{array}{l}\text { CdTe semiconductor } \\
\text { layer }\end{array}$ & $\beta=-0.135$ & $2.5 \mu \mathrm{m} \mathrm{CdTe}$ & $1 \mu \mathrm{m} \mathrm{CdTe}$ & $\begin{array}{l}\text { Previous LCAs of CdTe PV } \\
{[8,45,46]}\end{array}$ \\
\hline Solar glass & $\beta=-0.063$ & $3.2 \mathrm{~mm}$ & $2.2 \mathrm{~mm}$ & $\begin{array}{l}\text { Previous LCAs of CdTe PV } \\
{[8,49]}\end{array}$ \\
\hline 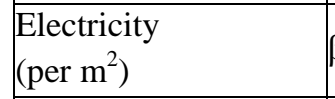 & $\beta=-0.44$ & $29 \mathrm{kWh}$ & $19 \mathrm{kWh}$ & $\begin{array}{l}\text { Previous LCAs of CdTe PV } \\
{[45,46]}\end{array}$ \\
\hline $\begin{array}{l}\text { Capital costs of } \\
\text { semiconductor } \\
\text { machinery }\left(\text { per } \mathrm{m}^{2}\right)\end{array}$ & $\begin{array}{l}\text { Negligible observed } \\
\text { change, } \\
\text { assumed } \beta \sim-0.50\end{array}$ & $\$ 24$ & $\$ 11$ & \multirow{3}{*}{$\begin{array}{l}\text { National renewable energy } \\
\text { lab (NREL) benchmarking } \\
\text { studies }[44,47]\end{array}$} \\
\hline $\begin{array}{l}\text { Value added (profit, } \\
\text { labor and } \\
\text { maintenance per } \mathrm{m}^{2} \text { ) }\end{array}$ & $\gamma=-1.53$ & $\$ 53$ & $\$ 22$ & \\
\hline Other direct inputs & Not considered & -\$26 & Unknown & \\
\hline Upstream value added & assumed $\gamma \sim-0.15$ & & & $\begin{array}{l}\text { Value added of each sector } \\
\text { estimated based on CEDA } \\
\text { database [50] }\end{array}$ \\
\hline \begin{tabular}{|l|} 
Upstream electricity, \\
transportation and \\
other inputs
\end{tabular} & $\begin{array}{l}\beta \text { is assumed to be } \\
\beta \sim-0.15\end{array}$ & & & Assumption \\
\hline Total module cost & $\beta=-0.29$ & $\begin{array}{l}\sim \$ 128 \\
\sim 0.98\end{array}$ & Unknown & $\begin{array}{l}\text { Observed learning rate for } \\
\text { thin film PV from 2006-2013 } \\
{[43]}\end{array}$ \\
\hline
\end{tabular}

Next, we construct a dynamic life-cycle assessment model for a simplified CdTe module to compute the total costs and GHG emissions of $1 \mathrm{~W}$ of CdTe following equations (11) and (12). The initial inputs to CdTe PV modules and their embodied life-cycle GHG emissions are based on the author's previous work, and were computed using the ecoinvent 2.2 and CEDA 4.0 life- 
cycle inventory databases [49,50]. Major inputs considered include the production of glass, semiconductor grade CdTe, electricity, wiring device manufacturing, fabricated metal manufacturing, semiconductor machinery manufacturing and truck transportation. The SI includes further details on observed learning parameters $(\beta$ and $\gamma)$ for CdTe components, data used in the scenario analysis and equations used to compute the costs and GHG emissions in each year of the scenario.

Figure 1 presents the model forecasts for CdTe module efficiency (a), costs (b) and lifecycle GHGs(c) alongside known benchmark values assuming VAL and IIL of $\beta$ and $\gamma=-0.15$ for upstream processes. Model results show that the costs of CdTe modules decline from around $\$ 0.98$ to $\$ 0.49$ per Watt as cumulative installed capacity increases to $100 \mathrm{GW}$, corresponding to an overall learning rate of $14 \%$, which is relatively close to the recently observed learning rate of $19 \%$ [43]. At the same time, life-cycle GHG emissions decline from 0.48 to $0.29 \mathrm{~kg} \mathrm{CO}_{2^{-}}$ equivalent per Watt with a learning rate of $13 \%$, an average reduction of $4 \mathrm{~g} \mathrm{CO}_{2}$-equivalent for every cent of cost reduced. The difference between the observed learning rate and the modeled learning rate can be due to a number of factors, including the longer time horizon of our model, recent declines in the price of tellurium and cost reductions occurring in the supply chain of inputs for which we consider no learning effects (making up 20\% of current module costs). 


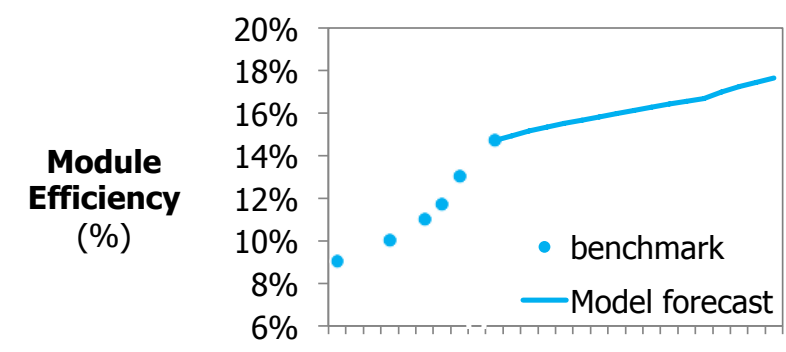

(a)

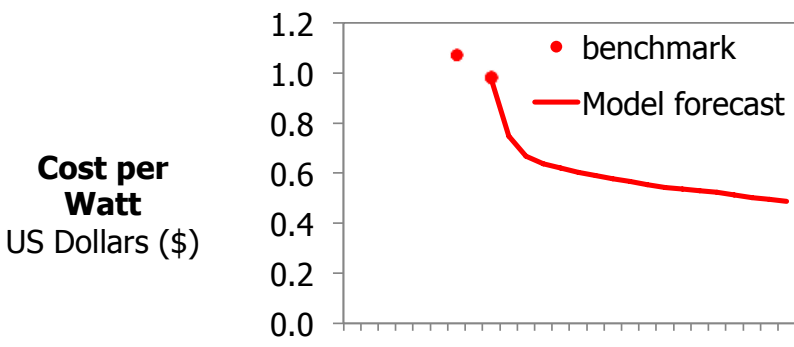

(b)

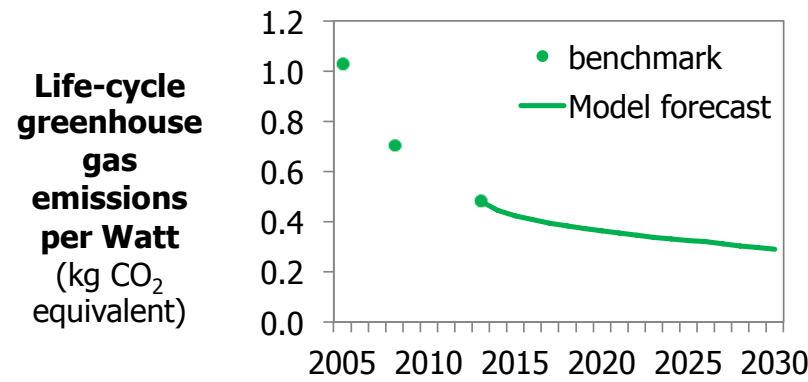

(c)

Figure 1. Model forecasts of module efficiency (a), costs (b) and life-cycle greenhouse gas emissions (c) per Watt power of CdTe PV from 2013-2030. DIL and VAL learning parameters ( $\beta$ and $\gamma$ ) for upstream processes (everything except PV module production) are assumed to be $\mathbf{- 0 . 1 5}$.

Figure 2 explores how the IIL $(\beta)$ and VAL $(\gamma)$ of upstream supply-chain processes can influence cost and GHG forecasts for CdTe PV by 2030. The assumed learning rates ( $\beta$ and $\gamma$ ) for upstream processes were varied from zero (no learning) to -0.30 . This variation can add an additional $0.5 \%$ to the GHG learning rate and $1 \%$ to the cost learning rate forecasted by the model. This translates to a cost reduction of up to $4 \%$ and a GHG emissions reduction of up to $2 \%$ compared to 2013 just from upstream processes. In this example, the largest supply chain reductions occurred in the glass and semiconductor machinery manufacturing sectors. 

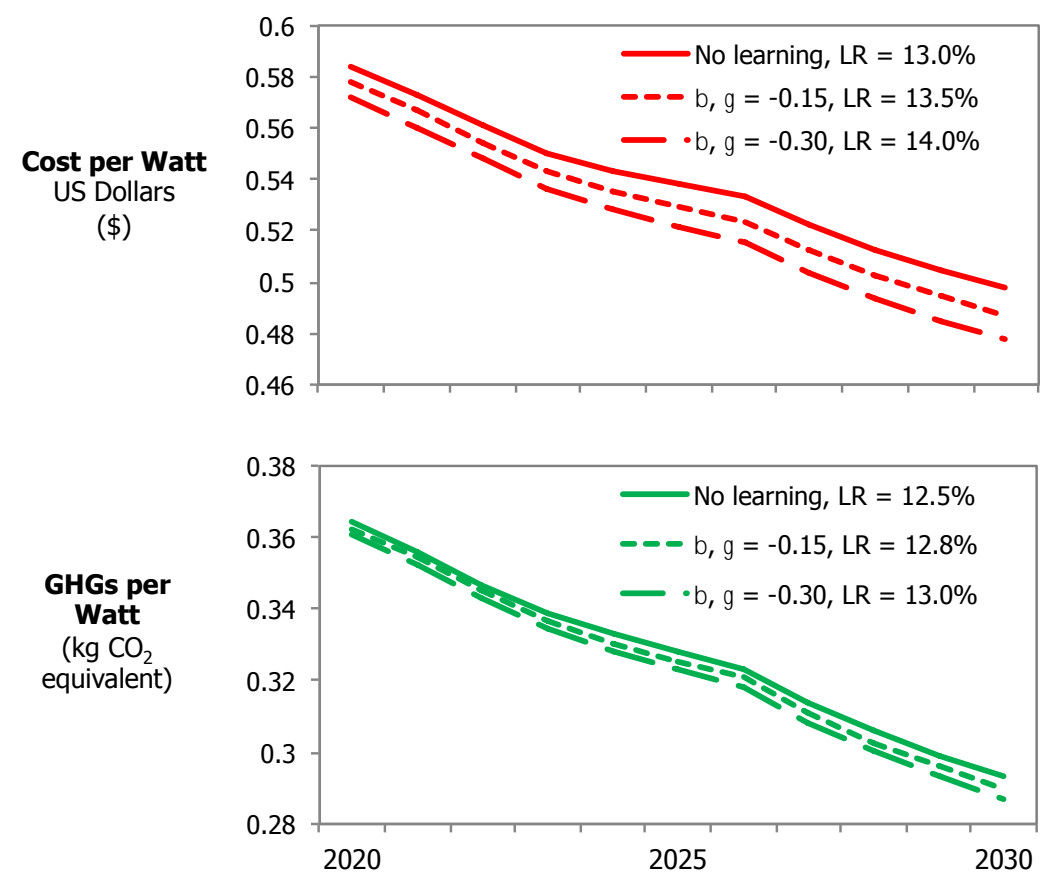

Figure 2. Variations in model forecasts from different learning rates assumed for upstream process (all processes other than CdTe module production).

It is important to note that this simplified example does not account for technological changes in all supply chain processes. The omission of electricity and transportation in particular suggest that learning in the supply chain could realize additional reductions in costs and greenhouse gas emissions than shown here. In sum, this example for CdTe PV shows that indirect learning upstream in the supply chain has smaller effects on observed reductions than direct learning in PV module production, but these indirect learning effects could be important to consider at large scales of technology deployment. 


\section{Discussion and conclusions}

In this article we presented a new framework for technological learning that incorporates the effects of changes in the direct and supply chain inputs to producing a technology. This framework can be used to examine the effects of different drivers of technological change throughout the supply chain of a technology. It is also shown that such a framework can be used to forecast the changes in environmental impacts and resource requirements of a technology.

The case study for CdTe PV suggests that accounting for technological changes throughout the supply chain could be important when forecasting the long-term environmental impacts of technologies under different policy conditions and technological scenarios. In some cases, as seen for CdTe PV, knowledge of the cost structure and technological limits of a technology may help explain the overall learning rates observed for a technology over time. It is also shown that technology learning can occur throughout the supply chain as the production of intermediate inputs to a technology grows. Also the demand for those intermediate inputs by other technologies and sectors would in turn influence the costs and environmental impacts of the technology in question. Such economy-wide effects may partly explain why the recent observations of the overall learning rate for thin-film PV were slightly higher than the estimates of our model.

Here we identify and discuss two major findings that may have policy-relevant implications on the assessment of the costs and environmental impacts of emerging and rapidly developing technologies.

Firstly, the life cycle environmental impacts of a technology can change as it progresses down its learning curve, but environmental impacts do not necessarily change at the same rate as costs. Power law relationships are helpful for forecasting how technologies change as a function of their cumulative production, and these relationships can be observed in the changes to physical inputs to a technology as well as in the technology's total costs (i.e. the traditional version of Wright's law). Deriving these relationships requires empirical observation of how inputs change 
over time as well as knowledge of technical and thermodynamic limits, as shown in the CdTe example. The supply chain learning framework proposed this article can be particularly useful when forecasting the aggregate or cumulative environmental impacts and resource requirements of technologies over the course of different policy scenarios. For example, under a climate change mitigation scenario, greater demand for PV power would result in faster reductions in costs and life cycle environmental impacts than under a business-as-usual scenario. This framework offers an advance in the modeling of technological change in LCA, where most current studies account for technological changes by assuming that technological maturity is reached by some year in the future that expert judgment deems reasonable, as in the authors' previous work $[3,8]$.

Secondly, increased production of one technology can lead to further-reaching cost reductions throughout its supply chain, and can lead to cost reductions in other technologies that use the same inputs. Our results indicate that accelerated technology learning is possible if a major cost driver of a technology is demanded by other technologies outside the domain of the technology in question. A possible example of this effect is the case of polycrystalline silicon (poly-silicon). Poly-silicon is a major input to both the semiconductor and photovoltaic solar industry [51], with PV demand for poly-silicon having only eclipsed other semiconductor applications (e.g. computing) in recent years. It is conceivable, that the growth of poly-silicon production for semiconductors in the 1990s could have resulted in indirect cost reductions in the PV modules, and that recent growth in poly-silicon demand in the PV industry has induced some technological learning and cost reductions in the semiconductor industry, although empirical studies would be needed to verify this hypothesis. Similarly, the growth in demand for mobile devices using lithium ion batteries may help advance technologies that will make electric vehicles or large-scale electricity storage more viable. The policy implication of this finding is that investments in research and development $(R \& D)$ or increased demand for alternative technologies (such as renewable energy portfolio standards) might lead to cost reductions 
benefitting other technologies and sectors that are not accounted for by traditional learning curve analysis.

The supply chain learning framework presented in this article would be particularly useful for incorporating technological learning into energy scenario models that consider environmental impacts and resource constraints in addition to just costs. The practical application of this framework depends on the availability of historical data on the inputs to certain technologies over time. LCA studies diligently track these inputs since they are used to calculate life cycle environmental impacts. For many technologies of interest, however, only a handful of published LCA studies might exist, which would present a challenge for applying this supplychain learning framework in those cases. Further, every technology is likely to be affected differently by learning in their upstream supply-chain processes, due to the varying contributions of supply chain processes to overall costs and environmental impacts. More research is needed to further test the hypothesis of this new learning framework, which would involve tracking the changing quantities of physical and labor inputs to major technologies and industrial processes and sectors over time to estimate IIL and VAL rates. Of particular interest would be tracking the changing costs of a common input to two different technologies. Pertinent examples would include lithium ion batteries utilized by both mobile computing devices and electric vehicles or crystalline silicon used in both computer and photovoltaic applications.

\section{Acknowledgements}

The authors acknowledge Yi Yang for his helpful comments. We also acknowledge the reviewers for their useful suggestions. This material is based upon work supported by the National Science Foundation under Grant No. CBET-1331438, and by the United States Environmental Protection Agency (EPA) STAR Grant No. 83557901. 


\section{References}

[1] Edenhofer O, Pichs-Madruga R, Sokona Y, Farahani E, Kadner S, Seyboth K, et al. Climate Change 2014: Mitigation of Climate Change. Contribution of Working Group III to the Fifth Assessment Report of the Intergovernmental Panel on CLimate Change. Cambridge University Press, Cambridge, United Kingdom and New York, NY, USA: IPCC; 2014.

[2] International Energy Agency. Energy Technology Perspectives 2012. OECD/IEA, Paris; 2012.

[3] Hertwich EG, Gibon T, Bouman EA, Arvesen A, Suh S, Heath GA, et al. Integrated life-cycle assessment of electricity-supply scenarios confirms global environmental benefit of low-carbon technologies. Proc Natl Acad Sci 2014. doi:10.1073/pnas.1312753111.

[4] Wright TP. Factors Affecting the Cost of Airplanes. J Aeronaut Sci 1936;3:122-8. doi:10.2514/8.155.

[5] Nagy B, Farmer JD, Bui QM, Trancik JE. Statistical Basis for Predicting Technological Progress. PLoS ONE 2013;8:e52669. doi:10.1371/journal.pone.0052669.

[6] Gavankar S, Suh S, Keller AA. The Role of Scale and Technology Maturity in Life Cycle Assessment of Emerging Technologies: A Case Study on Carbon Nanotubes. J Ind Ecol 2015;19:51-60. doi:10.1111/jiec.12175.

[7] Parkinson SC, Djilali N. Long-term energy planning with uncertain environmental performance metrics. Appl Energy 2015;147:402-12. doi:10.1016/j.apenergy.2015.02.006.

[8] Bergesen JD, Heath GA, Gibon T, Suh S. Thin-Film Photovoltaic Power Generation Offers Decreasing Greenhouse Gas Emissions and Increasing Environmental Cobenefits in the Long Term. Environ Sci Technol 2014;48:9834-43. doi:10.1021/es405539z.

[9] Bergesen JD, Tähkämö L, Gibon T, Suh S. Potential long-term global environmental implications of efficient light-source technologies (accepted). J Ind Ecol 2015.

[10] Arrow KJ. The economic implications of learning by doing. Rev Econ Stud 1962:155-73.

[11] van Eijck J, Batidzirai B, Faaij A. Current and future economic performance of first and second generation biofuels in developing countries. Appl Energy 2014;135:115-41. doi:10.1016/j.apenergy.2014.08.015.

[12] Zheng C, Kammen DM. An innovation-focused roadmap for a sustainable global photovoltaic industry. Energy Policy 2014;67:159-69. doi:10.1016/j.enpol.2013.12.006.

[13] Yao X, Liu Y, Qu S. When will wind energy achieve grid parity in China? Connecting technological learning and climate finance. Appl Energy n.d. doi:10.1016/j.apenergy.2015.04.094.

[14] Battke B, Schmidt TS. Cost-efficient demand-pull policies for multi-purpose technologies - The case of stationary electricity storage. Appl Energy 2015;155:334-48. doi:10.1016/j.apenergy.2015.06.010. 
[15] Ajanovic A, Haas R. On the future prospects and limits of biofuels in Brazil, the US and EU. Appl Energy 2014;135:730-7. doi:10.1016/j.apenergy.2014.07.001.

[16] Nakata T, Sato T, Wang H, Kusunoki T, Furubayashi T. Modeling technological learning and its application for clean coal technologies in Japan. Appl Energy 2011;88:330-6. doi:10.1016/j.apenergy.2010.05.022.

[17] Rochedo PRR, Szklo A. Designing learning curves for carbon capture based on chemical absorption according to the minimum work of separation. Appl Energy 2013;108:383-91. doi:10.1016/j.apenergy.2013.03.007.

[18] McNerney J, Farmer JD, Redner S, Trancik JE. Role of design complexity in technology improvement. Proc Natl Acad Sci 2011;108:9008-13.

[19] Mercure J-F. FTT:Power $\square$ : A global model of the power sector with induced technological change and natural resource depletion. Spec Sect Front Sustain 2012;48:799-811. doi:10.1016/j.enpol.2012.06.025.

[20] Agusdinata DB, Zhao F, Ileleji K, DeLaurentis D. Life Cycle Assessment of Potential Biojet Fuel Production in the United States. Environ Sci Technol 2011;45:9133-43. doi:10.1021/es202148g.

[21] Moore G. Progress in digital integrated electronics. vol. 21, IEEE; 1975, p. 11-3.

[22] Fishbone LG, Abilock H. Markal, a Linear-Programming Model for EnergySystems Analysis - Technical Description of the Bnl Version. Int J Energy Res 1981;5:353-75.

[23] Fishbone LG, Giesen G, Goldstein G, Hymmen H, Stocks K, Vos H, et al. User's guide for MARKAL (BNL/KFA Version 2. 0). A multi-period, linear-programming model for energy systems analysis. Brookhaven National Lab., Upton, NY (USA). Applied Science Dept.; Kernforschungsanlage Juelich GmbH (Germany, FR); 1983.

[24] Argote L, Epple D. Learning curves in manufacturing. Science 1990;247:920-4.

[25] Berndt ER. The practice of econometrics: classic and contemporary. AddisonWesley Reading, MA; 1991.

[26] Goddard C. Debunking the learning curve. Compon Hybrids Manuf Technol IEEE Trans On 1982;5:328-35.

[27] Sinclair G, Klepper S, Cohen W. What's experience got to do with it? Sources of cost reduction in a large specialty chemicals producer. Manag Sci 2000;46:28-45.

[28] Nordhaus WD. The perils of the learning model for modeling endogenous technological change. National Bureau of Economic Research; 2009.

[29] Berglund C, Söderholm P. Modeling technical change in energy system analysis: analyzing the introduction of learning-by-doing in bottom-up energy models. Energy Policy 2006;34:1344-56.

[30] Pan H. Dynamic and endogenous change of input-output structure with specific layers of technology. Struct Change Econ Dyn 2006;17:200-23. doi:10.1016/j.strueco.2005.05.003.

[31] Pan H, Köhler J. Technological change in energy systems: Learning curves, logistic curves and input-output coefficients. Ecol Econ 2007;63:749-58.

[32] Ferioli F, Schoots K, van der Zwaan BC. Use and limitations of learning curves for energy technology policy: A component-learning hypothesis. Energy Policy 2009;37:2525-35. 
[33] Yu CF, van Sark WGJHM, Alsema EA. Unraveling the photovoltaic technology learning curve by incorporation of input price changes and scale effects. Renew Sustain Energy Rev 2011;15:324-37. doi:10.1016/j.rser.2010.09.001.

[34] Hellweg S, Milà i Canals L. Emerging approaches, challenges and opportunities in life cycle assessment. Science 2014;344:1109-13. doi:10.1126/science.1248361.

[35] Sandén BA, Karlström M. Positive and negative feedback in consequential lifecycle assessment. J Clean Prod 2007;15:1469-81. doi:10.1016/j.jclepro.2006.03.005.

[36] Caduff M, Huijbregts MAJ, Koehler A, Althaus H-J, Hellweg S. Scaling Relationships in Life Cycle Assessment. J Ind Ecol 2014;18:393-406. doi:10.1111/jiec.12122.

[37] Walser T, Demou E, Lang DJ, Hellweg S. Prospective Environmental Life Cycle Assessment of Nanosilver T-Shirts. Environ Sci Technol 2011;45:4570-8. doi:10.1021/es2001248.

[38] Caduff M, Huijbregts MAJ, Althaus H-J, Koehler A, Hellweg S. Wind Power Electricity: The Bigger the Turbine, The Greener the Electricity? Environ Sci Technol 2012;46:4725-33. doi:10.1021/es204108n.

[39] Caduff M, Huijbregts MAJ, Althaus H-J, Hendriks AJ. Power-Law Relationships for Estimating Mass, Fuel Consumption and Costs of Energy Conversion Equipments. Environ Sci Technol 2011;45:751-4. doi:10.1021/es103095k.

[40] Dietzenbacher E. Spillovers of Innovation Effects. J Policy Model 2000;22:27-42. doi:10.1016/S0161-8938(97)00107-5.

[41] Suh S, Huppes G. Methods for Life Cycle Inventory of a product. J Clean Prod 2005;13:687-97. doi:10.1016/j.jclepro.2003.04.001.

[42] Leontief WW. Structure of American economy, 1919-1929 1941.

[43] Fraunhofer Institute. Photovoltaics Report. Freiberg, Germany: Fraunhofer Institute for Solar Energy Systems ISE; 2014.

[44] Woodhouse M, Goodrich A, Margolis R, James T, Dhere R, Gessert T, et al. Perspectives on the pathways for cadmium telluride photovoltaic module manufacturers to address expected increases in the price for tellurium. Sol Energy Mater Sol Cells 2013;115:199-212. doi:10.1016/j.solmat.2012.03.023.

[45] Fthenakis VM. Life cycle impact analysis of cadmium in CdTe PV production. Renew Sustain Energy Rev 2004;8:303-34.

[46] Fthenakis V, Kim HC, Frischknecht R, Raugei M, Sinha P, Stucki M. Life Cycle Inventories and Life Cycle Assessment of Photovoltaic Systems, PVPS Task 12, Report T12-02:2011. International Energy Agency (IEA); 2011.

[47] Woodhouse M, Lokanc M, James TL, Goodrich A, Mann M, Margolis R. The Present, Mid-Term, and Long-Term Supply Curves for Tellurium; Updates in the Results from NREL's CdTe PV Module Manufacturing Cost Model; and Module Recycling. NREL/PR-6A20-60430 2014.

[48] First Solar. First Solar PV Modules 2015. http://www.firstsolar.com/Home/Technologies-and-Capabilities/PV-Modules (accessed June 2, 2015).

[49] Ecoinvent Database v2.2. Ecoinvent Centre. Swiss Centre for Life Cycle Inventories, Switzerland; 2010.

[50] Suh S. Comprehensive Environmental Data Archive (CEDA) v.4 2009. 
[51] Global Demand for Polysilicon to Surge 25\% in 2014, According to NPD Solarbuzz. Solarbuzz.com 2014. http://www.solarbuzz.com/News/recentfindings/global-demand-polysilicon-surge-25-2014-according-npd-solarbuzz. 